\title{
Stakeholder Conflict Amplification of Large-Scale Engineering Projects in China: An Evolutionary Game Model on Complex Networks
}

\author{
Zhengqi He $\mathbb{D}^{1,2}$ Dechun Huang, ${ }^{1,2}$ Junmin Fang $\mathbb{D}^{1},{ }^{1}$ and Bo Wang $\mathbb{D}^{3}$ \\ ${ }^{1}$ Business School, Hohai University, Nanjing 211100, China \\ ${ }^{2}$ Jiangsu Provincial Collaborative Innovation Center of World Water Valley and Water Ecological Civilization, \\ Nanjing 211100, China \\ ${ }^{3}$ Business School, North Minzu University, Yinchuan 750021, China \\ Correspondence should be addressed to Junmin Fang; fangjunmin@hhu.edu.cn
}

Received 29 April 2020; Revised 6 July 2020; Accepted 17 July 2020; Published 5 August 2020

Guest Editor: Yuetang Bian

Copyright (C) 2020 Zhengqi He et al. This is an open access article distributed under the Creative Commons Attribution License, which permits unrestricted use, distribution, and reproduction in any medium, provided the original work is properly cited.

\begin{abstract}
Large-scale engineering projects make tremendous contributions to China's social and economic development; meanwhile, due to the diversity of stakeholders, the dispersion of time and space, and the complexity of information dissemination, large-scale engineering projects are easy to cause conflicts among stakeholders that affect social stability. The previous studies on stakeholder conflicts of large-scale engineering projects mainly focused on the game model among stakeholders, without considering the influence of stakeholders' interaction complex networks formed by social relations on the conflict amplification. For the two main stakeholders of the government and the resident that play a key role in China's large-scale engineering projects, this paper constructs an evolutionary game model of the main stakeholder conflict amplification and analyzes the evolutionary results of the conflict between the government and the resident in different situations. The small-world network is chosen as the complex network type of the simulation study since it is very similar with the topology of the realistic social network. Based on the NetLogo simulation platform, the stakeholder conflict amplification process of large-scale engineering projects on the small-world network is analyzed, and relevant management measures are proposed to defuse the stakeholder conflict of large-scale engineering projects. By using the evolutionary game model on complex networks, this paper studies the stakeholder conflict on the small-world network, providing reference for stakeholder conflict management of large-scale engineering projects in China.
\end{abstract}

\section{Introduction}

It is generally believed that large-scale engineering project is initiated by the government, along with many stakeholders involved in during the planning and implementation. It has the characteristics of large investment scale, many factors involved, wide range of influence, and so on, which has significant and far-reaching impact on regions and even the whole country $[1,2]$. As one of the most important driving forces for China' economic growth, the construction of large-scale engineering project has made tremendous contributions to China's economic and social development, and it is also an important means and tool for stable growth and macrocontrol in China's central government and local government. In recent years, large-scale engineering projects such as large water conservancy and hydropower projects, large-scale energy projects, and transportation infrastructure projects start to construct in succession. Taking transportation infrastructure projects as an example, three hundred and three programs had been highly promoted from 2016 to 2018, with an investment scale of 4.7 trillion RMB. The large-scale engineering project is a complex system with multisubjects and multiprograms, and the management decision environment of which faces many challenges such as spacious dispersion, stakeholder diversity, and the complexity of information dissemination, covering the "troika" that triggered group incidents: land acquisition and demolition, labor disputes, and environment pollution. 
The conflicts caused by large-scale engineering projects have become an important realistic problem that China urgently needs to solve. In the report of the 19th National Congress of the Communist Party of China, the CPC pointed out that it should "firmly fight the hard battle against major risks" and proposed that it should "strengthen the construction of mechanisms for preventing and resolving social contradictions." Undoubtedly, the amplification of stakeholder conflicts in large-scale engineering projects is also a major risk, and with the interest relations of some interest groups not been properly dealt with, the prominent social contradictions will appear, resulting in various social conflicts such as group incidents and thus leading to the disorder of the social systems. The large-scale engineering projects have the characteristics of stakeholder diversification, which includes not only the internal multisubjects of project management such as the government, project legal persons, and contractors, but also the external multisubjects of project management such as land acquisition and demolition, scholars, and social organizations. The main conflicts include internal multisubject conflicts, internal and external crossed conflicts, and external multisubject conflicts. In the context of China's special social transformation, social conflicts triggered by the large-scale engineering projects occurred frequently, such as Sichuan Hanyuan Incident, Chongqing Wanzhou 10.18 Incident, Yunnan Suijiang 3.25 Incident, Nantong Drainage Project Group Event, and Sichuan Shifang 7.2 Incident, and all of which were caused during the project construction. The large-scale engineering projects have always been the focus of social concern all over the world, and thus, social conflicts are easy to occur if problems caused by large-scale engineering projects are not handled properly [3]. The amplification of these conflicts will not only affect the progress of the project but also may lead the project to be eventually cancelled [4]. At the same time, it will also have certain impact on social stability and affect the harmonious development of social economy [5].

\section{Literature Review}

From the perspective of the scale and complexity, projects can be divided into three levels of large, medium, and small, among which the large-scale engineering projects are the largest and most complex. At present, there is no consensus on the specific classification criteria for large-scale engineering projects. Flyvbjerg [2] believed that with the development of economy, the investment amount of largescale engineering projects should reach at least one billion dollars. $\mathrm{Hu}$ et al. [6] studied the classification criteria for investment quotas of large-scale engineering projects in European countries, the United States, South Korea, China, and other countries, thinking that a project with an investment quota of $0.01 \%$ of the total national GDP can be considered as a large-scale engineering project. In China, there are many projects that exceed these standards. For example, the total investment amount of the BeijingShanghai high-speed railway project reached 220 billion
$\mathrm{RMB}$, and the total investment amount of the South-toNorth Water Transfer Project reached 500 billion RMB.

Due to the development of social economy, the scale of large-scale engineering projects is getting larger and larger, and thus, more and more participants are involved in the construction, such as the government, project developers, contractors, constructors, nearby residents, relocated residents, and general public are considered to be stakeholders [7-9]. The structure of relationships among them becomes more and more complex, and the conflicts become more and more serious [10]. One of the most important reasons is the difference in stakeholders' interests resulting from differences in stakeholders' status [11]. Scholars divide the types of stakeholders and determine their status from stakeholders' responsibility in project management and their ranking of rights in engineering projects $[12,13]$. The most common way is to divide stakeholders into internal stakeholders and external stakeholders [14] and to study them separately $[15,16]$. Traditionally, it focuses more on internal stakeholder conflicts. Through a literature review and questionnaire survey, Awwad et al. [17] studied reasons for and solution to internal stakeholder conflicts in large-scale construction projects in the Middle East. On the other hand, Lee et al. [18] believe that conflicts among external stakeholders have become a more important factor affecting the success of the project, and by taking 22 representative largescale public engineering projects in Korea as research objects, he proposes management framework of the external stakeholder conflict.

In China, stakeholder conflicts in large-scale engineering projects are mainly reflected in the contradiction between the public's interest appeals and the government and project legal person's decisions [19]. Unbalanced interests among stakeholders may cause social conflicts, leading to social events such as group incidents. Social transformation usually leads to the adjustment of the interests of social members, which will inevitably lead to the increase in social conflicts. In recent years, with the social transformation and upgrading of China, there have been more and more group incidents caused by large-scale engineering projects, such as the PX events in cities such as Xiamen, Dalian, and Qingdao in China. Group incident is a word with Chinese characteristics, and the meaning of which is similar to the "collective action" in Western sociology. Although Western scholars have not formed a consensus on its definition, they all emphasize that collective action is the action taken by a kind of group for a common goal (generally to improve their own conditions, such as obtaining higher social status, more material conditions, and etc.) $[20,21]$. For collective action triggered by large-scale engineering projects, scholars' research focuses on two aspects. On the one hand, a large number of scholars identify the factors that trigger collective action and use social network analysis, social risk management framework, and other methods to determine its key factors $[5,22]$. On the other hand, many scholars study the "not-in-my-backyard" phenomenon of large-scale engineering projects [23-25]. The large-scale engineering projects are generally beneficial to the vast majority of the public, 
but which is often opposed by the local people. This is called the "not-in-my-backyard" phenomenon [26].

Although China has a social, economic, and political background that is not completely consistent with Western society, the research on collective actions triggered by largescale engineering projects in China is mainly focused on factors that lead to collective action and the phenomenon of "Not-In-My-Backyard". Taking the Sanmenxia Dam Project and the South-to-North Water Transfer Project in China as a case study, Liu et al. [27] use questionnaires, semistructured interviews, and structural equation models to study the causes of collective action in China's large construction projects. By systematically summarizing the NIMBY phenomenon and combining with the background of China's large-scale engineering projects, Wang [28] believes that risk perception and risk amplification are the main causes of social conflicts. Liu et al. [23] use China's 2,500 questionnaires to study whether the NIMBY phenomenon is the main reason for the resident to oppose the construction of urban infrastructure projects in China, and conclude that depriving the resident's participation rights is the main reason for collective action. In addition, many Chinese scholars analyze the evolution process of resident incidents based on incidents triggered by large-scale engineering projects and propose corresponding prevention strategies and governance strategies $[29,30]$.

Conflicts are caused by imbalances in interests among stakeholders, and thus, coordinating the relationship among stakeholders is the key to resolving conflicts. Game theory is often used to study the relationship among engineering project stakeholders and resolve conflicts [31-33]. Barough et al. [34] study the application of prisoner's dilemma and chicken game in construction projects and consider that studying stakeholders' relations with game theory is very helpful for conflict management of engineering projects. Kang et al. [35] construct a three-stage game auction model to analyze the relationship between the government and the bidding in the public-private partnership projects. Based on the game theory, Wu et al. [36] construct a decision model for the conflict behavior between the owner and the contractor, compare the results under the two different conditions of nonconflict and conflict, and study the influences of conflict behavior of large-scale engineering projects on project performance. There are already many Chinese scholars who use the game theory to study the conflicts among stakeholders of large-scale Chinese engineering projects [37-39], but most of which are studied under a homogeneous social network structure. However, the connections among individuals in realistic life are not completely random but have complex network characteristics of small world and scale-free [40, 41]. Based on social relations such as interpersonal relationships, stakeholders of largescale engineering project form a complex interactive relation network with characteristics of the complex network. Nowak and May [42] study the prisoner's dilemma game on the twodimensional square, and by combining the complex network theory with the game theory, he proposes the space game theory; thus, the evolutionary game research on the complex network begins to get a lot of concern $[43,44]$. At present, the study of evolutionary games on complex networks mainly focuses on two aspects. Firstly, under the specific network structure, the effects of different evolution rules on the evolution results are studied, such as imitating the best rule and imitating the winner rule. Secondly, there are already many scholars who have been made on the influence of different network structures on the game results, such as rule network, scale-free network, and small-world network and $[45,46]$. In addition, many scholars have carried out targeted research in different fields such as finance and society. Liu and Wang [47] constructed the coevolution model of social network structure and strategy according to the topology of social network and made a case study by using the NetLogo social network simulation platform. Based on the network association structure of investors, Bian et al. [48] established the simulation and evolution model of herding behavior in the stock market under the strategy of the coordination game in the network and studied the key factors that influence the change of investment behavior of stock market investors from the perspective of the network. Based on consumers' different preferences for electric vehicles, Fang et al. [49] divided consumers into three types of stakeholders to considering the time-varying demand of electric vehicle charging stations and gas stations, and studied the construction of electric vehicle charging infrastructure in the evolutionary game model of small-world complex networks. Therefore, based on the identification of the major stakeholders of large-scale engineering projects, this paper builds a game model about the evolution of stakeholder conflicts amplification, carries out simulation research on complex network to explore the impacts of factors such as complex network characteristics on the result of evolutionary game.

\section{Evolutionary Game Model on Stakeholder Conflict Amplification in Large-Scale Engineering Projects}

3.1. Model Hypothesis. Although there are many stakeholders in large-scale engineering projects, including governments, project developers, contracts, constructors, nearby residents, relocated residents, and general public, only some of which play a key role in different problems. For the social conflicts and social stability risks caused by engineering projects, the stakeholders who play a key role are usually the core stakeholders such as the government, project developers, and the resident $[8,9,50]$. In China, large-scale engineering projects are generally led by the government, while project developers undertake specific tasks such as project planning, fund raising, and construction implementation. Especially, for the handling of social conflicts such as resident incidents, it involves the basic interests of the resident and the government's emergency management capabilities, which is mainly a game between the government and the resident. During this process, project developers mainly assist in relevant work of the government departments. Most of China's current largescale engineering project conflict research studies, group 
event evolution research studies, and other related research studies are based on the game between the government and the resident. For example, Liu et al. take the urban demolition group events as the research object and take the government and the resident as both sides of the game to study the conflict evolution of the urban demolition group events [29]. Song and Liu [51] constructed a game model between local governments and protesters and studied the mechanism of resolving group events. Based on existing research, this paper considers the actual situation in China, highlighting the key stakeholders in the group events caused by large-scale engineering project conflicts. On the other hand, this paper considers the complexity of the model, simplifying the model so that the conflict evolution process and results can be shown more clearly. Therefore, this paper mainly considers the government and the resident as both sides of the evolutionary game. The basic hypothesis of the evolutionary game model of the stakeholder conflict amplification is as follows:

(1) In the evolutionary game model, the two participating groups are the resident $(A)$ and the government $(B)$.

(2) When related conflicts occur in large-scale engineering projects, the resident has two strategies of rational negotiation and violent resistance, namely, the strategic space of the resident is $S_{A}=$ \{rational negotiation $A_{1}$, violent resistance $\left.A_{2}\right\}$. Moreover, due to the differences of the local people in social and economic status and social relations, the attitudes toward large-scale engineering projects are also different. The resident take decentralized actions in the strategic space \{rational negotiation $A_{1}$, violent resistance $\left.A_{2}\right\}$. Most people understand the construction of large-scale engineering projects and choose rational negotiation, while some small parts take excessive behavior for violent struggle. This hypothesis also conforms to participants' conventional behaviors in the evolutionary game, and a small part of the participants adopts hypothesis of attempting behavior by the trial-and-error method.

(3) Due to differences in governance concepts, political achievements, and support degree for large-scale engineering projects, there are two strategies of compromised acceptance and tough control in response to the reaction of the resident, namely, the strategic space of the government which is $S_{B}=\left\{\right.$ compromise acceptance $B_{1}$, tough control $\left.B_{2}\right\}$. In this game, the government will be affected by higher-level governments and public opinions; thus, the strategies adopted will be constantly adjusted.

(4) According to the government's relevant guarantees and interest compensation, the resident will make decisions of rational negotiation or violent resistance, which is in line with the "myopia" hypothesis on the decision of evolutionary games. The resident will observe the benefits with corresponding decisions made by the people around them as a reference for their own decisions. Similarly, when the government responds to the reaction of the resident, it will also make strategic adjustments on the basis of the situations of the previous round.

3.2. Dynamic Evolutionary Game Flow and Replication Dynamic Equation. The specific game flow of the stakeholder conflict amplification and evolution in large-scale engineering projects is shown in Figure 1, which is mainly divided into two stages. In the first stage, when conflict issues occur, the resident should either support the project and adopt rational negotiation strategy for their own related demands (namely, A1), or they do not understand the project or worry that the project construction will affect the ecological environment and their own interests, thus adopting violent resistance strategy for their own related demands (namely, A2). When facing different strategies of the resident, the government either chooses compromised acceptance strategy (namely, B1) or tough control strategy (namely, B2).

Before the implementation of large-scale engineering projects, the resident and the government have certain retained earnings, which are, respectively, recorded as $R_{A}$ and $R_{B}$. If both parties adopt moderate strategies (the resident adopts rational negotiation strategy, and the government adopts compromised acceptance strategy), the increased total revenue caused by the large-scale engineering project is $R$, and the proportion of the resident is $\alpha(0<\alpha<1)$. The total cost paid during the moderate negotiation process between the two parties is $C$, and the share proportion of the resident is $\beta(0<\beta<1)$. Generally speaking, large-scale engineering projects have a greater role in promoting local, social, and economic development, so we believe that $R>C$. When the resident adopts rational negotiation strategy and the government adopts tough control strategy, neither party can obtain the increased revenue from the large-scale engineering projects. Due to the attempt to adopt negotiation strategy, the resident will still need to pay the corresponding cost under mild negotiation. Because the government adopts tough control strategy and does not need to bear the cost under a moderate negotiation state, it needs to increase the maintenance expenditure $\Delta S$ for the tough control. In the process, it also gets the additional income $\Delta R_{B}$ from the project. When the resident chooses the violent resistance strategy and the government chooses compromised acceptance strategies, the resident needs to bear the cost of violent resistance $\Delta L$, but they will also receive additional compensation $\Delta R_{A}$ from the project. At this time, as the government tries to adopt the compromised acceptance strategy, and it needs to pay the corresponding cost under the mild negotiation. When the resident chooses violent resistance strategy and the government chooses the tough control strategy, both parties should undertake extra cost of violent resistance and maintenance expenditure for their strong attitude, but at the same time, they can also get additional income and interest compensation from the project. The payoff matrix of the evolutionary game between 


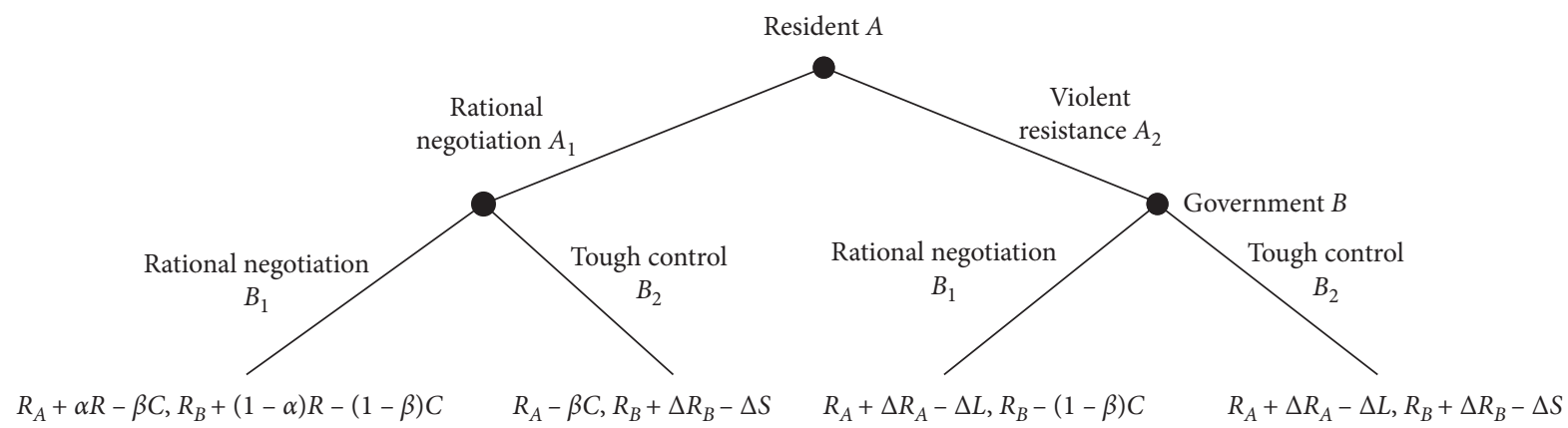

FIgURE 1: Dynamic flow of evolutional game between the resident and the government in large-scale engineering projects.

the resident and the government of the large-scale engineering projects is shown in Table 1.

Assuming that the proportion of rational negotiation strategy $A 1$ adopted by the resident is $x$ and that of compromised acceptance strategy $B 1$ adopted by the government is $y$, the expected revenue of rational negotiation strategy $A 1$ and violent resistance strategy $A 2$ adopted by resident are, respectively,

$$
\begin{aligned}
& U_{A 1}=y \alpha R+R_{A}-\beta C, \\
& U_{A 2}=R_{A}+\Delta R_{A}-\Delta L .
\end{aligned}
$$

The expected revenue of the compromised acceptance strategy $B 1$ and tough control strategy $B 2$ that the government adopts are, respectively,

$$
\begin{aligned}
& U_{B 1}=x(1-\alpha) R+R_{B}-(1-\beta) C, \\
& U_{B 2}=R_{B}+\Delta R_{B}-\Delta S .
\end{aligned}
$$

It can get that the expected revenue of the resident and the government is, respectively,

$$
\begin{aligned}
& U_{A}=x\left(y \alpha R-\Delta R_{A}-\beta C+\Delta L\right)+R_{A}+\Delta R_{A}-\Delta L, \\
& U_{B}=y\left[x(1-\alpha) R-\Delta R_{B}-(1-\beta) C+\Delta S\right]+R_{B}+\Delta R_{B}-\Delta S .
\end{aligned}
$$

It can further get that the replicated dynamic equations of the resident and government are, respectively,

$$
\begin{aligned}
& \frac{\mathrm{d} x}{\mathrm{~d} t}=x(1-x)\left(y \alpha R-\Delta R_{A}-\beta C+\Delta L\right), \\
& \frac{\mathrm{d} x}{\mathrm{~d} t}=y(1-y)\left[x(1-\alpha) R-\Delta R_{B}-(1-\beta) C+\Delta S\right] .
\end{aligned}
$$

In can be known from formula (6) that when $x=0,1$ or

$$
y=\frac{\Delta R_{A}+\beta C-\Delta L}{\alpha R},
$$

the resident can achieve partial stability by adopting the rational negotiation strategy; from formula (7), when $y=0,1$ or

$$
x=\frac{\Delta R_{B}+(1-\beta) C-\Delta S}{(1-\alpha) R},
$$

the government can adopt compromised acceptance strategy to achieve partial stability. Thus, five partial equilibrium points are formed:

$$
\begin{array}{r}
E_{1}(0,0), E_{2}(1,0), E_{3}(0,1), E_{4}(1,1), \\
E_{5}\left(\frac{\Delta R_{B}+(1-\beta) C-\Delta S}{(1-\alpha) R}, \frac{\Delta R_{A}+\beta C-\Delta L}{\alpha R}\right) .
\end{array}
$$

The Jacobi matrix replicated can be obtained by replicated dynamic equations (6) and (7):

$$
J=\left[\begin{array}{cc}
(1-2 x)\left(y \alpha R-\Delta R_{A}-\beta C+\Delta L\right) & x(1-x) \alpha R \\
y(1-y)(1-\alpha) R & (1-2 y)\left[x(1-\alpha) R-\Delta R_{B}-(1-\beta) C+\Delta S\right]
\end{array}\right]
$$

It can get that the determinants $\operatorname{det} J$ and $\operatorname{tr} J$ of the Jacobi matrix are, respectively,

$$
\begin{aligned}
\operatorname{det} J & =(1-2 x)(1-2 y)\left(y \alpha R-\Delta R_{A}-\beta C+\Delta L\right)\left[x(1-\alpha) R-\Delta R_{B}-(1-\beta) C+\Delta S\right]-x y(1-x)(1-y) \alpha R(1-\alpha) R, \\
\operatorname{tr} J & =(1-2 x)\left(y \alpha R-\Delta R_{A}-\beta C+\Delta L\right)+(1-2 y)\left[x(1-\alpha) R-\Delta R_{B}-(1-\beta) C+\Delta S\right] .
\end{aligned}
$$


TABLE 1: The payoff matrix of the evolutionary game between the resident and the government.

\begin{tabular}{lcc}
\hline Resident $A$ & Compromised acceptance $B 1$ & Government $B$ \\
& $R_{A}+\alpha R-\beta C, R_{B}+(1-\alpha) R-(1-\beta) C$ & Tough control $B 2$ \\
\hline Rational negotiation $A 1$ & $R_{A}+\Delta R_{A}-\Delta L, R_{B}-(1-\beta) C$ & $R_{A}-\beta C, R_{B}+\Delta R_{B}-\Delta S$ \\
Violent resistance $A 2$ & $R_{A}+\Delta R_{A}-\Delta L, R_{B}+\Delta R_{B}-\Delta S$ \\
\hline
\end{tabular}

It can get that the determinant and trace of the Jacobi matrix at five equilibrium points are shown in Table 2.

$$
\text { Note: } T=\frac{-\left(\Delta R_{A}+\beta C-\Delta L\right)\left[\Delta R_{B}+(1-\beta) C-\Delta S\right]\left\{(1-\alpha) R-\left[\Delta R_{B}+(1-\beta) C-\Delta S\right]\left\{\alpha R-\left(\Delta R_{A}+\beta C-\Delta L\right)\right\}\right\}}{(1-\alpha) R \alpha R} \text {. }
$$

3.3. Multiscenario Evolutionary Game Analysis. After obtaining the replication dynamic equation, the next step is to analyze the evolutionary game equilibrium state of the resident and the government in the large-scale engineering project and its dynamic adjustment process under different scenarios (the situation that the government's extra stability expenditures $\Delta S$ are different from the resident's violent resistance cost $\Delta L$ ).

3.3.1. Scenario One. The government's extra stability expenditure $\Delta S$ and the resident's violent resistance cost $\Delta L$ are very large.

If both the resident and the government adopt tough strategies, causing the government's extra stability expenditure and the resident's violent resistance cost large, then

$$
\begin{array}{r}
\Delta S>(1-\alpha) R>\Delta R_{B}+(1-\beta) C \\
\Delta L>\alpha R>\Delta R_{A}+\beta C .
\end{array}
$$

Substituting above equations into the resident' dynamic replication equation (7) and the government's replication dynamic equation (8), it gets $\mathrm{d} x / \mathrm{d} t>0, \mathrm{~d} y / \mathrm{d} t>0$. In the $2 \times$ 2 strategic space of the resident and the government, the evolutionary phase map is shown in Figure 2(a), and the equilibrium result of the evolutionary game between the resident and the government is the only Nash equilibrium (rational negotiate $A 1$, compromised acceptance $B 1$ ).

When the government's extra stability expenditure $\Delta S$ and the resident's violent resistance cost $\Delta L$ are large, both the resident and the government will try to avoid adopting strategies that lead to deterioration of the situation (namely, violent resistance and tough control) but will resolve conflicts through rational negotiation, in hope to gain the total social revenue from the successful implementation of the project.

3.3.2. Scenario Two. The government's extra stability expenditure $\Delta S$ and the resident's violent resistance cost $\Delta L$ are very small.

If both the resident and the government adopt tough strategies, causing the government's extra stability expenditure $\Delta S$ and the resident's violent resistance cost $\Delta L$ very small, then

$$
\begin{aligned}
(1-\alpha) R> & \Delta R_{B}+(1-\beta) C>\Delta S, \\
& \alpha R>\Delta R_{A}+\beta C>\Delta L .
\end{aligned}
$$

For replication dynamic equation (6) of the resident, if

$$
y^{*}=\frac{\Delta R_{A}+\beta C-\Delta L}{\alpha R}
$$

then $\mathrm{d} x / \mathrm{d} t=0,0<y^{*}<1$ is the mixed equilibrium point. When

$$
y>\frac{\Delta R_{A}+\beta C-\Delta L}{\alpha R},
$$

then $\mathrm{d} x / \mathrm{d} t=0, x \longrightarrow 1$ is the evolutionarily stable strategy. When

$$
y<\frac{\Delta R_{A}+\beta C-\Delta L}{\alpha R}
$$

then $\mathrm{d} x / \mathrm{d} t=0, x \longrightarrow 0$ is the evolutionarily stable strategy. if

For replication dynamic equation (7) of the government,

$$
x^{*}=\frac{\Delta R_{B}+(1-\beta) C-\Delta S}{(1-\alpha) R},
$$

then $\mathrm{d} x / \mathrm{d} t=0,0<x^{*}<1$ is the mixed equilibrium point. When

$$
x>\frac{\Delta R_{B}+(1-\beta) C-\Delta S}{(1-\alpha) R},
$$

then $\mathrm{d} x / \mathrm{d} t>0, y \longrightarrow 1$ is the evolutionarily stable strategy. When

$$
x<\frac{\Delta R_{B}+(1-\beta) C-\Delta S}{(1-\alpha) R},
$$

then $\mathrm{d} x / \mathrm{d} t<0, y \longrightarrow 0$ is the evolutionarily stable strategy.

In the $2 \times 2$ strategic space between the government and the resident, by judging the positive and negative values of the determinant det $J$ and the $\operatorname{tr} J$ of the five partial equilibrium points, the points $E_{1}(0,0)$ and $E_{4}(1,1)$ can be obtained as evolutionarily stable strategy, the points $E_{2}(1,0)$ and $E_{3}(0,1)$ as unstable equilibrium points, and the point 
TABLE 2: The determinant and trace of the Jacobi matrix at five equilibrium points.

\begin{tabular}{lcc}
\hline $\begin{array}{l}\text { Equilibrium } \\
\text { point }\end{array}$ & det $J$ & $\operatorname{tr} \mathrm{J}$ \\
\hline$E_{1}(0,0)$ & $\left(\Delta R_{A}+\beta C-\Delta L\right)\left[\Delta R_{B}+(1-\beta) C-\Delta S\right]$ & $-\left(\Delta R_{A}+\beta C-\Delta L\right)-\left[\Delta R \_B+(1-\beta) C-\Delta S\right]$ \\
$E_{2}(1,0)$ & $\left(\Delta R_{A}+\beta C-\Delta L\right)\left[(1-\alpha) R-\Delta R_{B}-(1-\beta) C+\Delta S\right]$ & $\left(\Delta R_{A}+\beta C-\Delta L\right)+\left[(1-\alpha) R-\Delta R_{B}-(1-\beta) C+\Delta S\right]$ \\
$E_{3}(0,1)$ & $\left(\alpha R-\Delta R_{A}-\beta C+\Delta L\right)\left[\Delta R_{B}+(1-\beta) C-\Delta S\right]$ & $\left(\alpha R-\Delta R_{A}-\beta C+\Delta L\right)+\left[\Delta R_{B}-(1-\beta) C+\Delta S\right]$ \\
$E_{4}(1,1)$ & $\left(\alpha R-\Delta R_{A}-\beta C+\Delta L\right)\left[(1-\alpha) R-\Delta R_{B}-(1-\beta) C+\Delta S\right]$ & $-\left(\alpha R-\Delta R_{A}-\beta C+\Delta L\right)-\left[(1-\alpha) R-\Delta R_{B}-(1-\beta) C+\Delta S\right]$ \\
$E_{5}\left(x^{*}, y^{*}\right)$ & $T$ & 0 \\
\hline
\end{tabular}

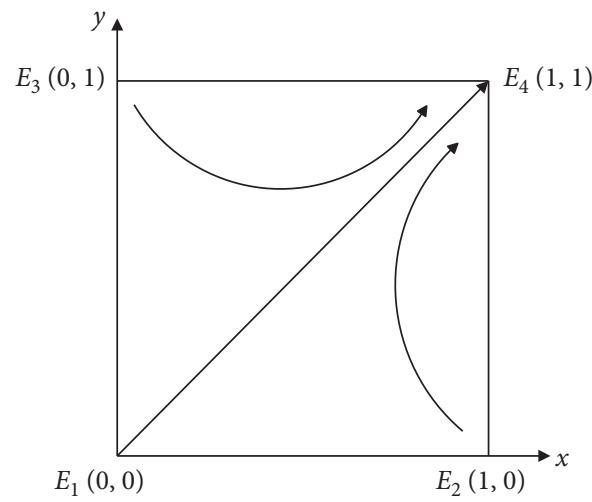

(a)

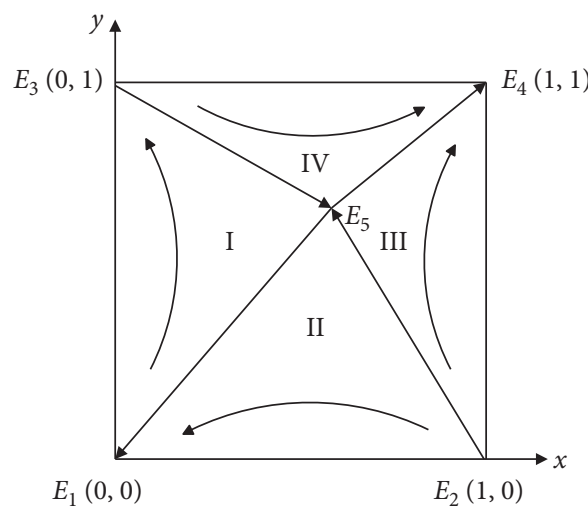

(c)

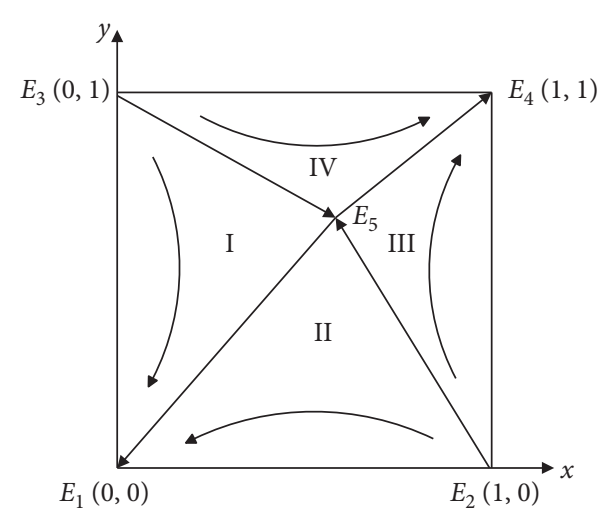

(b)

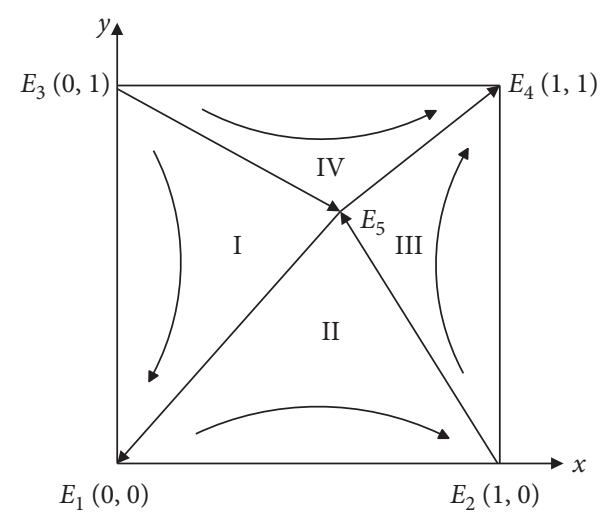

(d)

Figure 2: (a) The equilibrium result when both $\Delta S$ and $\Delta L$ are large; (b) the equilibrium result when both $\Delta S$ and $\Delta L$ are small; (c) the equilibrium result when $\Delta S$ is large and $\Delta L$ is small; (d) the equilibrium result when $\Delta S$ is small and $\Delta L$ is large.

$$
E_{5}\left(\frac{\Delta R_{B}+(1-\beta) C-\Delta S}{(1-\alpha) R}, \frac{\Delta R_{A}+\beta C-\Delta L}{\alpha R}\right)
$$

as unstable saddle points. The evolution phase diagram is shown in Figure 2(b).

When the government's extra stability expenditure $\Delta S$ and the resident's violent resistance cost $\Delta L$ are very small, the equilibrium result of the evolutionary game between the resident and the government in large-scale engineering projects is (rational negotiation $A 1$, compromised acceptance $B 1$ ) or (violent resistance $A 2$, tough control $B 2$ ), shown in Figure 2(b). The specific evolutionary results are influenced by the initial state of social systems such as the strength of the resident's attitude to the large-scale engineering projects, the expression manner of interest appeals and the government's ruling philosophy, and the handling habits of the interest appeals. When the initial state is located in region I and II in Figure 2(b) (namely, quadrangle E1E2E5E3), evolution will converge to the point $E_{1}(0,0)$; then, the resident adopts violent resistance strategy, and the government adopts tough control strategy. When the initial state is located in region III and IV in Figure 2(b) (namely, quadrangle E2E4E3E5), evolution will converge to the point $E_{4}(1,1)$; then, the resident adopts rational negotiation strategy, and the government adopts compromised acceptance strategy.

3.3.3. Scenario Three. The government's extra stability expenditure $\Delta S$ is large, and the resident's violent resistance cost $\Delta L$ is small. 
If both the resident and the government adopt tough strategies, causing the government's extra stability expenditure $\Delta S$ very large and the resident's violent resistance cost $\Delta L$ very small, then

$$
\begin{aligned}
\Delta S>(1-\alpha) R & >\Delta R_{B}+(1-\beta) C \\
\alpha R & >\Delta R_{A}+\beta C>\Delta L .
\end{aligned}
$$

For replication dynamic equation (6), when

$$
y^{*}=\frac{\Delta R_{A}+\beta C-\Delta L}{\alpha R},
$$

then $\mathrm{d} t / \mathrm{d} t=0,0<y^{*}<1$ is the mixed equilibrium point. When

$$
y>\frac{\Delta R_{A}+\beta C-\Delta L}{\alpha R},
$$

then $\mathrm{d} t / \mathrm{d} t>0, x \longrightarrow 1$ is the evolutionarily stable strategy. When

$$
y<\frac{\Delta R_{A}+\beta C-\Delta L}{\alpha R},
$$

then $\mathrm{d} t / \mathrm{d} t<0, x \longrightarrow 0$ is the evolutionarily stable strategy. For replication dynamic equation (7), no matter what value $x$ takes, $\mathrm{d} t / \mathrm{d} t>0$. Therefore, $y \longrightarrow 1$ is the evolutionary stable strategy.

In the $2 \times 2$ strategic space between the government and the resident, by judging the positive and negative values of the determinant det $J$ and the tr $J$ of the five partial equilibrium points, the points $E_{4}(1,1)$ can be obtained as evolutionarily stable strategy, points $E_{1}(0,0), E_{3}(0,1)$, and

$$
E_{5}\left(\frac{\Delta R_{B}+(1-\beta) C-\Delta S}{(1-\alpha) R}, \frac{\Delta R_{A}+\beta C-\Delta L}{\alpha R}\right)
$$

as unstable saddle points, and point $E_{2}(1,0)$ as unstable points. The evolution phase diagram is shown in Figure 2(c).

When the government's extra stability expenditure $\Delta S$ is large while the resident's violent resistance cost $\Delta L$ is small, the equilibrium result of the evolutionary game between the resident and the government in large-scale engineering projects is (national negotiation A1, compromised acceptance $B 1$ ), shown in Figure 2(c). Since the government's extra stability expenditure is large, the government will try not to adopt tough control to increase spending but tend to adopt compromised acceptance strategy. At this time, if the resident adopts violent resistance strategy, they will increase their expenditure on the one hand (although the cost of violent resistance is small, it is still greater than 0 ), and on the other hand, as $\alpha R>\Delta R_{A}+\beta C, \alpha R-\beta C>\Delta R_{A}$ is greater than 0 . The increase in revenue by adopting rational negotiation strategy is greater than that of the violent resistance strategy. Therefore, the resident will also tend to adopt the rational negotiation strategy.

3.3.4. Scenario Four. The government's extra stability expenditure $\Delta S$ is small, and the resident's violent resistance cost $\Delta L$ is large.
If both the resident and the government adopt tough strategies, causing the government's extra stability expenditure $\Delta S$ very small and the resident's violent resistance cost $\Delta L$ very large, then

$$
\begin{gathered}
(1-\alpha) R>\Delta R_{B}+(1-\beta) C>\Delta S, \\
\Delta L>\alpha R>\Delta R_{A}+\beta C .
\end{gathered}
$$

For resident replication dynamic equation (6), no matter what value $y$ takes, $\mathrm{d} x / \mathrm{d} t>0, x \longrightarrow 1$ is the evolutionary stable strategy. For government replication dynamic equation (7), when

$$
x^{*}=\frac{\Delta R_{B}+(1-\beta) C-\Delta S}{(1-\alpha) R},
$$

then $\mathrm{d} x / \mathrm{d} t=0,0<x^{*}<1$ is the mixed equilibrium point. When

$$
x>\frac{\Delta R_{B}+(1-\beta) C-\Delta S}{(1-\alpha) R},
$$

then $\mathrm{d} x / \mathrm{d} t>0, y \longrightarrow 1$ is the evolutionary stable strategy. When

$$
x<\frac{\Delta R_{B}+(1-\beta) C-\Delta S}{(1-\alpha) R},
$$

then $\mathrm{d} x / \mathrm{d} t<0, y \longrightarrow 0$ is the evolutionary stable strategy.

In the $2 \times 2$ strategic space between the government and the resident, by judging the positive and negative values of the determinant det $J$ and the tr $J$ of the five partial equilibrium points, the point $E_{4}(1,1)$ is obtained as the evolutionary stable state, points

$$
\begin{array}{r}
E_{1}(0,0), E_{2}(1,0), \\
E_{5}\left(\frac{\Delta R_{B}+(1-\beta) C-\Delta S}{(1-\alpha) R}, \frac{\Delta R_{A}+\beta C-\Delta L}{\alpha R}\right)
\end{array}
$$

as unstable saddle points, and point $E_{3}(0,1)$ as unstable points. The evolution phase diagram is shown in Figure 2(d).

When the government's extra stability expenditure $\Delta S$ is small and the resident's violent resistance cost $\Delta L$ is large, the equilibrium result of the evolutionary game between the resident and the government in large-scale engineering projects is (national negotiation $A 1$, compromised acceptance $B 1$ ), shown in Figure 2(d). Since the resident's violent resistance cost is large, the resident will try not to adopt violent resistance to increase expenditure but tend to adopt rational negotiation strategy. At this time, if the government adopts tough control strategy, they will increase their expenditure on the one hand (although the extra stability expenditure is small, it is still greater than 0$)$, and on the other hand, as $(1-\alpha) R>\Delta R_{B}+$ $(1-\beta) C,(1-\alpha) R>\Delta R_{B}+(1-\beta) C$ is greater than 0 . The increase in revenue by adopting compromised acceptance strategy is greater than that of tough control strategy. Therefore, the government will also tend to adopt compromised acceptance strategy. 


\section{Simulation Analysis of the Amplification of Stakeholder Conflict of Large-Scale Engineering Projects on Complex Networks}

4.1. Evolutionary Game Simulation Steps on Complex Networks. Since Watts and Strogatz studied the average path length and clustering coefficient of the nematode neural network, the American Western electrical power network, and the film actor cooperative network, they found that it had the characteristics of small world with average path length and large clustering coefficient and formally proposed the small-world network [39]. After long-term development, the small-world network has been proven to be effective in quantitatively studying the problems associated with complex social and economic systems. The network of multisubject conflict amplification of large-scale engineering projects is essentially a complex network based on the multisubject interaction of realistic social networks and influenced by external systems such as social economic environment. A large number of scholars studied the realistic social network on the basis of complex networks and found that its network topology had the characteristics of small world with small average path length and large clustering coefficient. In view of the fact that the small-world network can help to explain problems related to complex social and economic systems and that the realistic communication network is similar to the small-world network, the complex network structure type constructed in this paper is a small-world network.

For the simulation of the evolutionary game between the resident and the government in large-scale engineering projects on the complex network, firstly, we need to determine the strategic choice of individual players on the complex network, then analyze the impact of different network characteristics on the evolutionary game results, and explore the stakeholder conflict amplification mechanism of large-scale engineering projects.

Firstly, a WS small-world network with a certain number of nodes is generated, and network parameters are initialized. All nodes on the network are divided into the two categories of the resident and the government, and the proportion of nodes on the network between the resident and the government is given. The meaning of the government includes all levels of governments, government departments, and officials related to the large-scale engineering projects. Therefore, the government is not only a node but should also be regarded as multiple nodes on the network, and the number of which is much smaller than that of the resident nodes. In the initial state, the resident nodes randomly adopt the rational negotiation strategy $A_{1}$ or the violent resistance strategy $A_{2}$, and the government node randomly adopts the compromised acceptance strategy $B_{1}$ or the tough control strategy $B_{2}$.

Secondly, in each round of the game, each node on the complex network plays a game with all its neighbors, and the resident and the government will change their own strategies according to the updated rules after each round. The updated rule is as follows: the resident chooses to play games with its neighbors, if they are the same as the resident nodes; the strategy remains the same, if they are government nodes, and the probability that the resident node changes the strategy is

$$
p_{A}=\frac{1}{\left\{1+\exp \left[\left(U_{A 1}-U_{A 2}\right) / \varepsilon\right]\right\}} .
$$

The probability that the government node changes the strategy is

$$
p_{B}=\frac{1}{\left\{1+\exp \left[\left(U_{B 1}-U_{B 2}\right) / \varepsilon\right]\right\}} .
$$

$U_{A 1}, U_{A 2}, U_{B 1}$, and $U_{B 2}$ can be, respectively, obtained by equations (1)-(4). $\varepsilon$ denotes the noise coefficient, which indicates the interference of uncontrollable factors such as external impact on the node updating strategy. The larger the $\varepsilon$ is, the larger the interference is. Generally, $\varepsilon=0.5$ is taken.

Finally, the above game process is repeated until the state of each node on the network reaches a stable state. The simulation is terminated, and the simulation result is obtained.

4.2. Basic Variable Settings of NetLogo Simulation Platform. This paper uses the NetLogo simulation platform to carry out evolutionary game simulation research on the complex network. NetLogo is a multisubject programmable modeling environment that can be applied for natural and social phenomena. It can control thousands of individuals in modeling and can simulate the behavior of microindividuals, the emergence of macroscopic modes, and their relationships, which is especially suitable for simulating complex systems that evolve over time.

According to the algorithm steps of the evolutionary game simulation on the complex network, firstly, the WS small-world network is generated, and all the nodes on the network are divided into the two categories of the resident and the government. In the initial NetLogo interface, the initial parameters of the network can be determined by adjusting the sliders of each parameter, as shown in Figure 3.

In Figure 3, the relevant initial parameters of the model are on the left side. For example, "num-nodes" indicates the network scale, namely, the total number of subjects on the network. "Rewiring-probability" indicates the random reconnection probability $p$ of the WS small-world network. "Government-of-total-nodes" indicates the proportion of the government subjects on the network to the total subjects. "Initial- $x$ " indicates the proportion that the resident chooses rational negotiation strategies in the initial state. "Initial-y" indicates the proportion that the government chooses compromised acceptance in the initial state. "Citizen-ratioof-income-increase" indicates the proportion of the resident to the increased total revenue of the project for the society, and "citizen-ratio-of-cost" indicates the proportion of the government to the total cost of the project. "Total-incomeincrease" indicates the increased total revenue of the project for the society. "Total-cost" indicates the cost that ensures the project going smoothly. "Citizen-extra-income-force" indicates the additional revenue from the resident's violent 


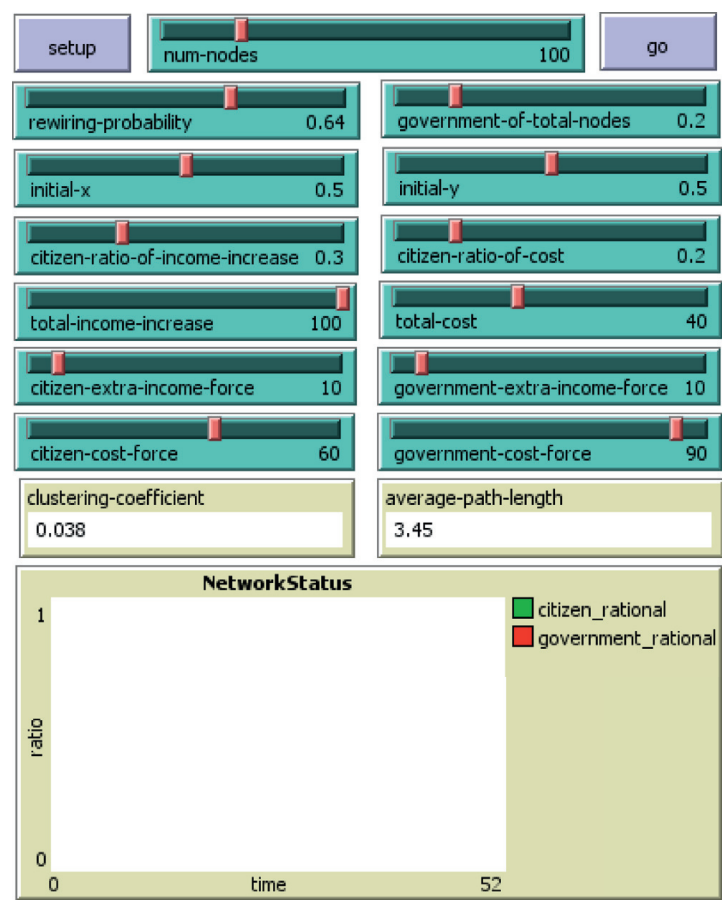

(a)

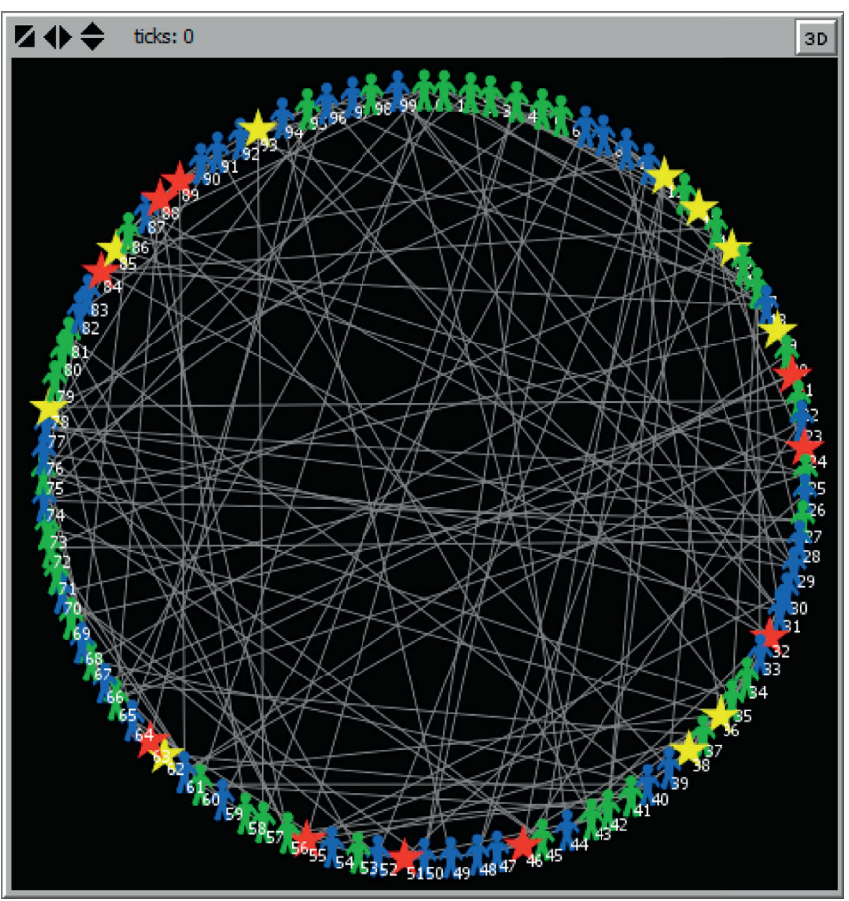

(b)

FIgURE 3: The initial state on the WS small-world network.

resistance. "Government-extra-income-force" indicates the additional revenue from the government's tough control. "Citizen-cost-force" indicates the cost of the resident's violent resistance. "Government-cost-force" indicates additional expenditure from the government's tough control. The right side of the figure represents the generated network, where "people" indicates the resident and "five-pointed star" represents the government. Among the resident subjects, the green indicates those who choose rational negotiation strategy and the blue indicates those who choose violent resistance strategy. Among the government subjects, the red indicates those who choose compromised acceptance strategy, and the yellow indicates those who choose tough control strategy.

In the initial state, it is assumed that the reconnection probability $p$ of small-world networks is 0.2 , the number of subjects on the whole network is 100 , to which the proportion of the government subjects is 0.2 , the proportion $x$ of the resident who adopts rational negotiation strategy is 0.3 , the proportion $y$ of the government who adopts compromised acceptance strategy is 0.5 , the increased proportion $\alpha$ of the resident to the total revenue is 0.3 , the proportion $\beta$ of the total cost that the resident share is 0.2 , the increased total revenue $R$ is 100 , the total cost $C$ is 40 , the initial retained revenue of the resident $R_{A}$ is 10 , the initial retained revenue of the government $R_{B}$ is 10 , the additional revenue $\Delta R_{A}$ obtained by the resident's violent resistance is 20 , and the additional revenue $\Delta R_{B}$ obtained by the government's tough control is 20 .

4.3. Simulation Result and Analysis. This paper will simulate the evolutionary game results of the government and the resident on the small-world network under different scenarios, and analyze the impact of different initial states and different network characteristics on the conflicts between the government and the resident subjects in large-scale engineering projects. With the start of the simulation, the color of the subjects in the network diagram on the right side of Figure 3 will gradually change with the start of the game, and the result will also be displayed in the lower left corner of Figure 3 on the "NetworkStatus". The abscissa indicates the evolution time, and the ordinate indicates the proportion of the rational resident. The green indicates the proportion of the resident who chooses rational negotiation, and the red indicates the proportion of the government who chooses compromised acceptance.

4.3.1. Scenario One. The government's extra stability expenditure $\Delta S$ and the resident's violent resistance cost $\Delta L$ are very large.

In scenario one, the condition $\Delta S>(1-\alpha) R>\Delta R_{B}+(1-\beta) C, \Delta L>\alpha R>\Delta R_{A}+\beta C \quad$ is satisfied, and the assumed parameter is set as follows: the resident's violent resistance cost $\Delta L$ is 40 and the government's extra stability expenditure $\Delta S$ of tough control is 80 . When the reconnection probability $p$ of the small-world network takes different values, the evolutionary results of the game between the resident and the government are shown in Figure 4 .

It can be seen from Figure 4 that when the reconnection probability $p$ of the small-world network takes different values, the evolutionary game trends of the resident and the government are basically the same, and the final equilibrium 


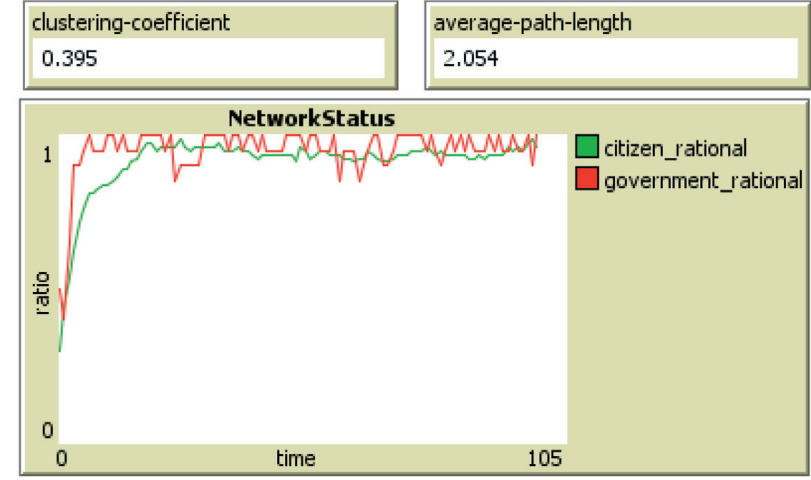

(a)

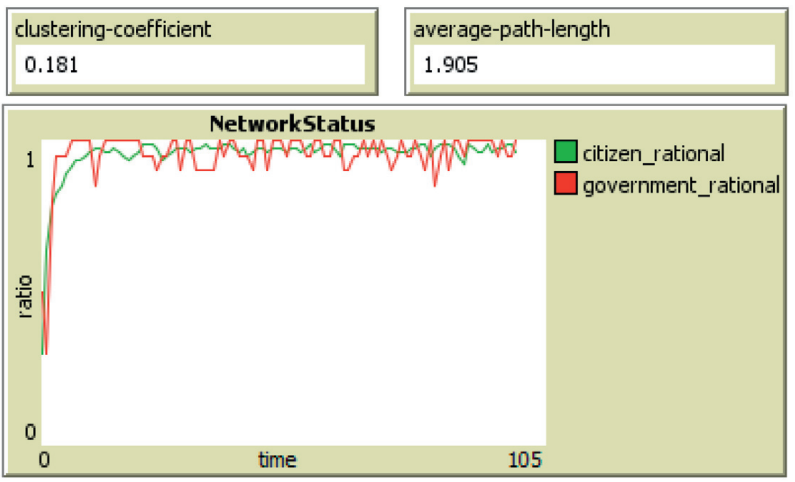

(c)

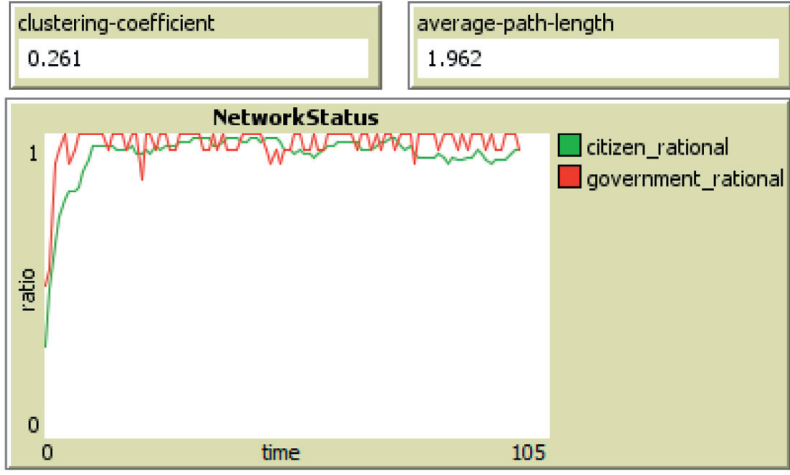

(b)

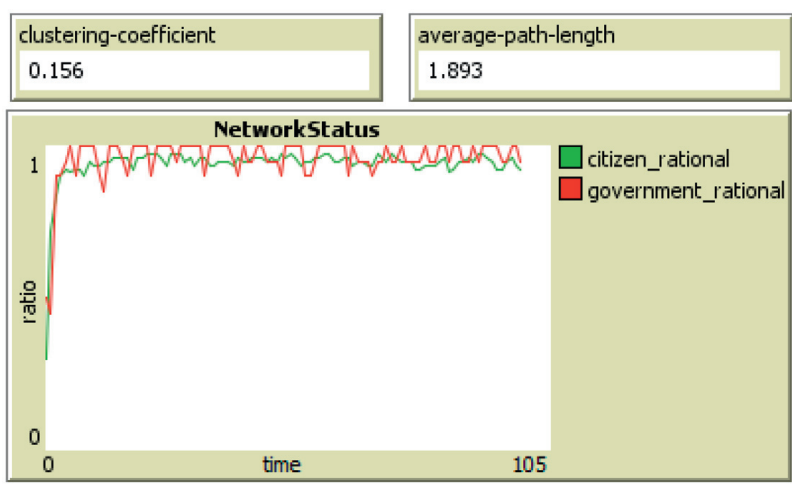

(d)

FIGURE 4: The evolutionary results when the reconnection probability $p$ takes different values in scenario one: (a) the evolutionary result when $p=0.2$; (b) the evolutionary result when $p=0.4$; (c) the evolutionary result when $p=0.6$; (d) the evolutionary result when $p=0.8$.

tends to (rational negotiation, compromise acceptance), but with the increase of reconnection probability, the time that they evolve to a stable state has been significantly reduced. When the reconnection probability $p$ is, respectively, 0.2 , $0.4,0.6$, and 0.8 , the network clustering coefficient is, respectively, $0.395,0.261,0.181$, and 0.156 , and the average path length is, respectively, 2.054, 1.962, 1.905, and 1.893, which indicates that with the increase of reconnection probability of the small-world network, the clustering coefficient and the average path length decrease. The decrease of the clustering coefficient indicates that the concentration degree of the conflict network between the resident and the government gets low, showing a decentralized state, and the heterogeneity among subjects is more prominent. Some subjects with large nodes have greater influence than other subjects, thus easier to reach the equilibrium state. The decrease of the average path length indicates that the scale of the network between the resident and the government gets small, the interaction closeness among the subjects gets increased, and it is easier to achieve equilibrium state.

4.3.2. Scenario Two. The government's extra stability expenditure $\Delta S$ and the resident's violent resistance cost $\Delta L$ are small.

In scenario two, the condition $(1-\alpha) R>\Delta R_{B}+$ $(1-\beta) C>\Delta S, \alpha R>\Delta R_{A}+\beta C>\Delta L$ is satisfied, and the assumed parameter is set as follows: the resident's violent resistance cost $\Delta L$ is 10 and the government's extra stability expenditure $\Delta S$ of tough control is 20 . When the reconnection probability $p$ of the small-world network takes different values, the evolutionary results of the game between the resident and the government are shown in Figure 5 .

It can be seen from Figure 5 that when the reconnection probability $p$ of the small-world network takes different values, the evolutionary game trends of the resident and the government are basically the same, and the final equilibrium tends to (violent resistance, tough control), but with the increase of reconnection probability, the time that they evolve to a relatively stable state has been gradually reduced. When the reconnection probability $p$ is, respectively, 0.2 , $0.4,0.6$, and 0.8 , the network clustering coefficient is, respectively, $0.416,0.233,0.18$, and 0.155 , and the average path length is, respectively, $2.08,1.931,1.907$, and 1.895. Similar to scenario one, it also shows that with the increase of reconnection probability of the small-world network, the clustering coefficient and the average path length decrease, making the heterogeneity among subjects more prominent. The interaction closeness among the subjects gets increased, and it is easier to achieve equilibrium state.

In the previous analysis, we know that the proportion $x$ that the resident adopts rational negotiation is 0.3 and the proportion $y$ that the government adopts compromised 


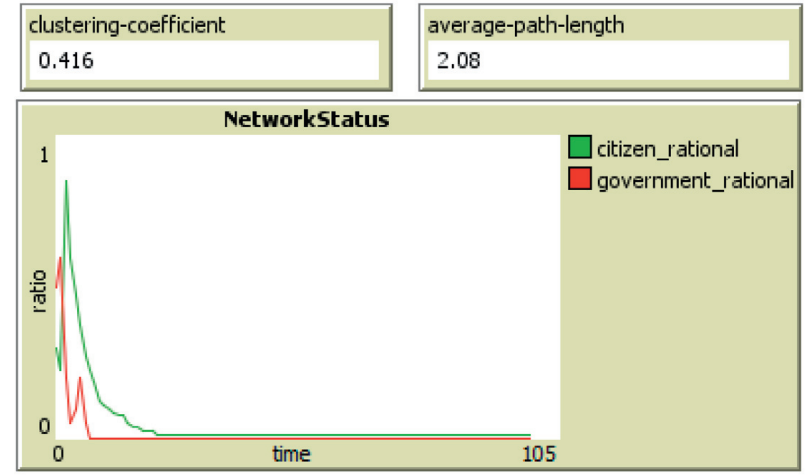

(a)

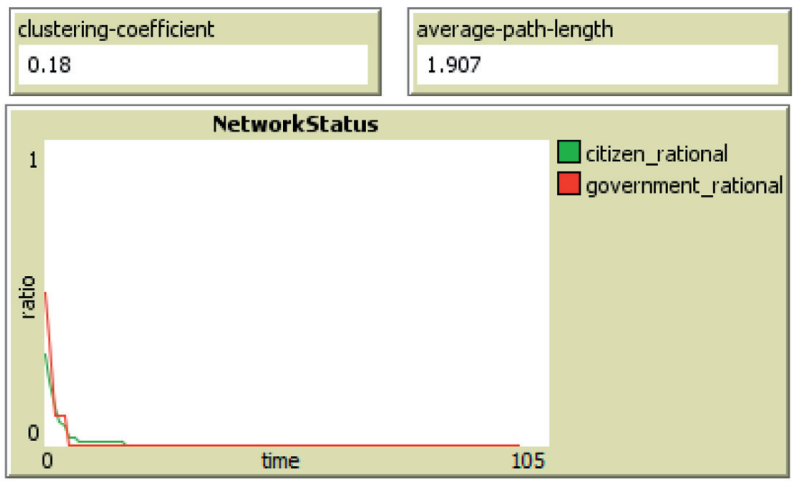

(c)

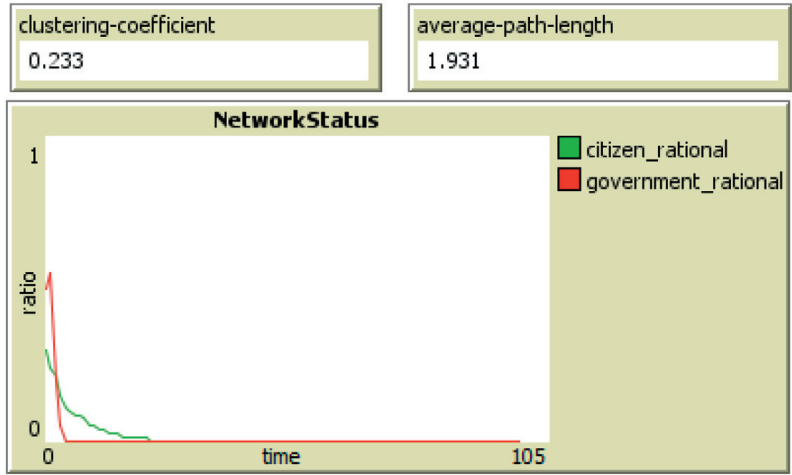

(b)

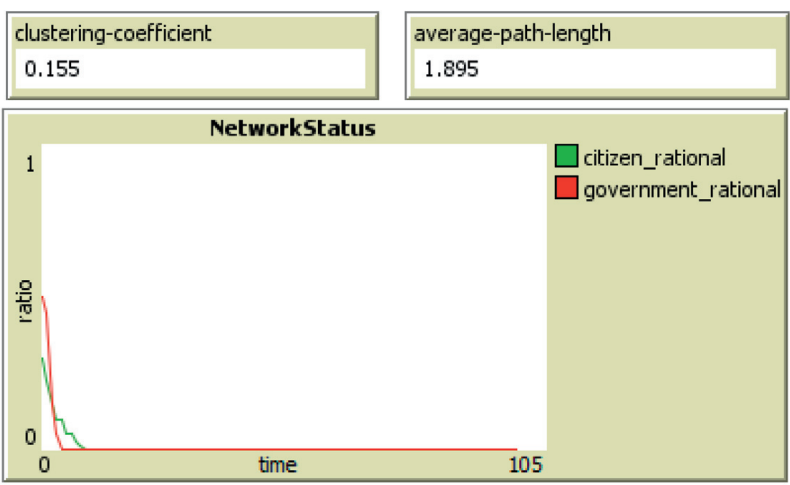

(d)

Figure 5: The evolutionary result when the reconnection probability $p$ takes different values in scenario two (the initial state is located in region I and II): (a) the evolutionary result when $p=0.2$; (b) the evolutionary result when $p=0.4$; (c) the evolutionary result when $p=0.6$; (d) the evolutionary result when $p=0.8$.

acceptance is 0.5 , and the state at this time is in region I and II of Figure 2(b), satisfying the convergence of evolution to (violent resistance, tough control). Next, we will simulate and analyze the evolution results when the initial state is in the regions III and IV of Figure 2(b). At this time, it is assumed that the proportion $x$ that the resident adopts rational negotiation is 0.6 and the proportion $y$ that the government adopts compromised acceptance is 0.8 , and the evolution result is shown in Figure 6.

It can be seen from Figure 6 that when the reconnection probability $p$ of the small-world network takes different values, the evolutionary game trends of the resident and the government are basically the same, and the final equilibrium tends to (rational negotiation, compromised acceptance), but with the increase of reconnection probability, the time that they evolve to a stable state has been gradually reduced, and the fluctuation decreases. When the reconnection probability $p$ of the small-world network is, respectively, 0.2 , $0.4,0.6$, and 0.8 , the network clustering coefficient is, respectively, $0.403,0.244,0.176$, and 0.152 , and the average path length is, respectively, 2.056, 1.948, 1.898, and 1.896. It also shows that with the increase of reconnection probability of the small-world network, the clustering coefficient and the average path length decrease, making the heterogeneity among subjects more prominent and the interaction closeness among the subjects increased, and it is easier to achieve equilibrium state.
4.3.3. Scenario Three. The government's extra stability expenditure $\Delta S$ is large, and the resident's violent resistance cost $\Delta L$ is small.

In scenario three, the condition $\Delta S>(1-\alpha) R>\Delta R_{B}+(1-\beta) C, \quad \alpha R>\Delta R_{A}+\beta C>\Delta L \quad$ is satisfied, and the assumed parameter is set as follows: the resident's violent resistance cost $\Delta L$ is 10 and the government's extra stability expenditure $\Delta S$ of tough control is 80 . When the reconnection probability $p$ of the small-world network takes different values, the evolutionary results of the game between the resident and the government are shown in Figure 7.

It can be seen from Figure 7 that when the reconnection probability $p$ of the small-world network takes different values, the evolutionary game trends of the resident and the government are basically the same, and the final equilibrium tends to (rational negotiation, compromised acceptance), but with the increase of reconnection probability, the fluctuation that they evolve to a stable state has been gradually reduced. When the reconnection probability $p$ of the small-world network is, respectively, $0.2,0.4,0.6$, and 0.8 , the network clustering coefficient is, respectively, 0.432 , $0.242,0.164$, and 0.158 , and the average path length is, respectively, $2.102,1.938,1.903$, and 1.897. It also shows that with the increase of reconnection probability of the smallworld network, the clustering coefficient and the average path length decrease. Similar to scenario one and two, the 


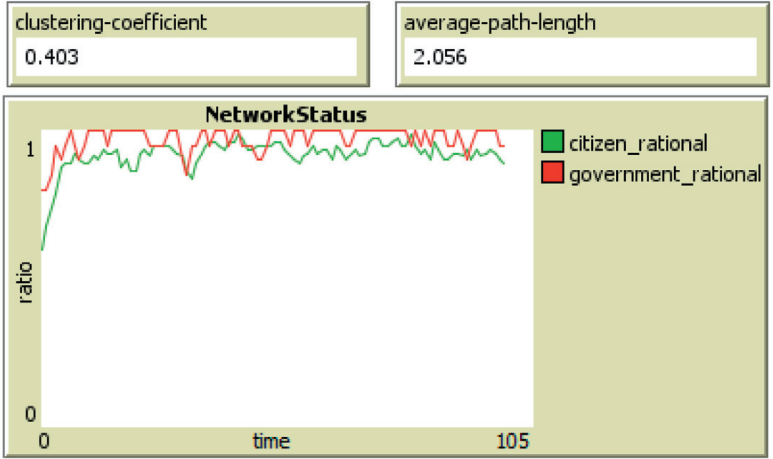

(a)

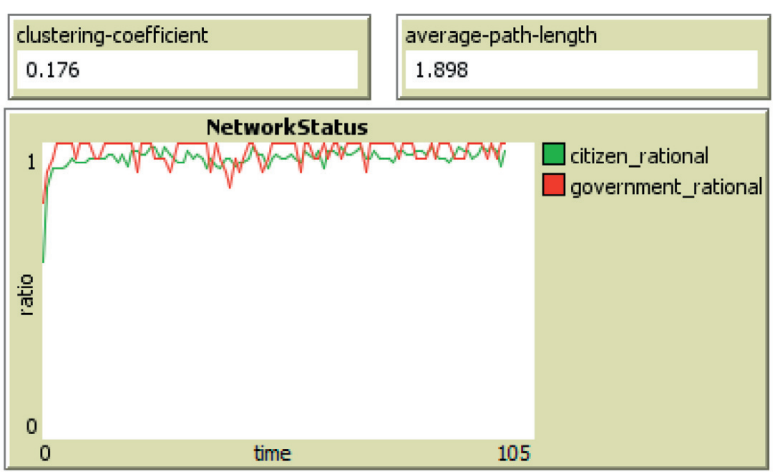

(c)

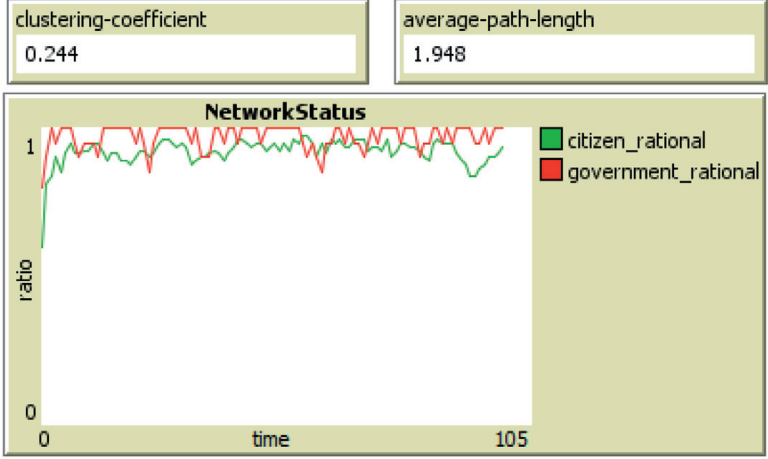

(b)

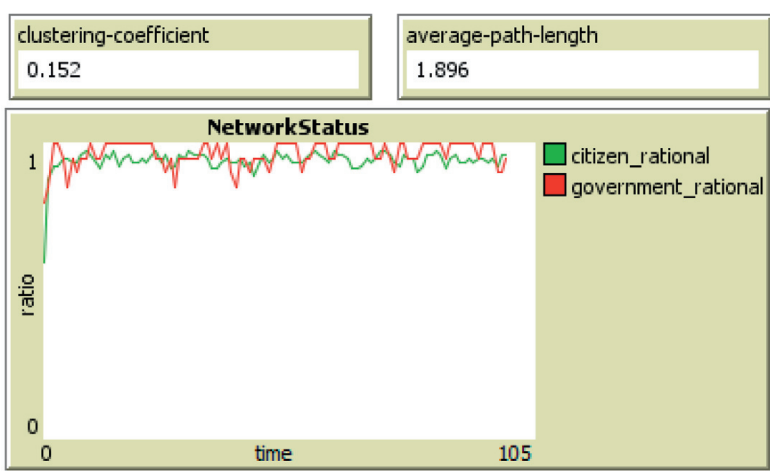

(d)

FIGURE 6: The evolutionary result when the reconnection probability $p$ of the small-world network takes different values under scenario two (the initial state is located in region III and IV): (a) the evolutionary result when $p=0.2$; (b) the evolutionary result when $p=0.4$; (c) the evolutionary result when $p=0.6$; (d) the evolutionary result when $p=0.8$.

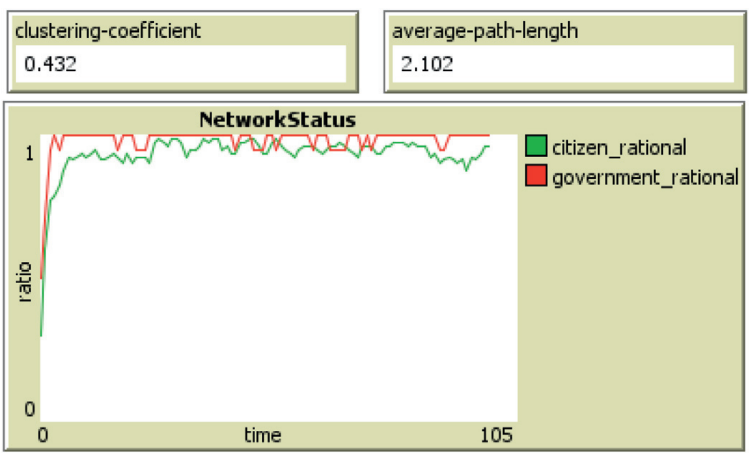

(a)

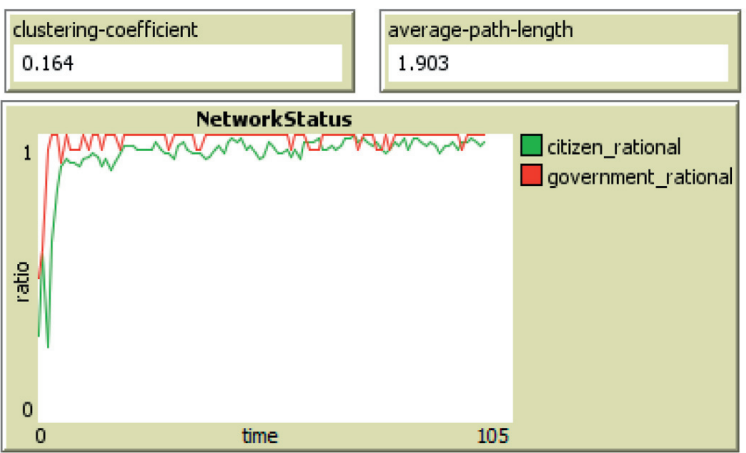

(c)

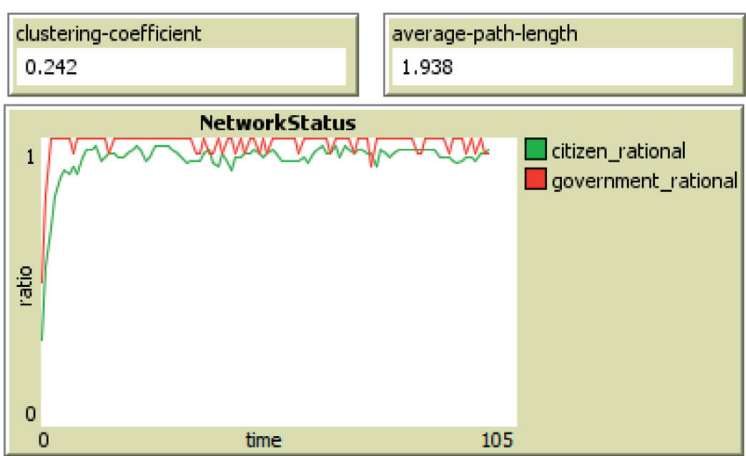

(b)

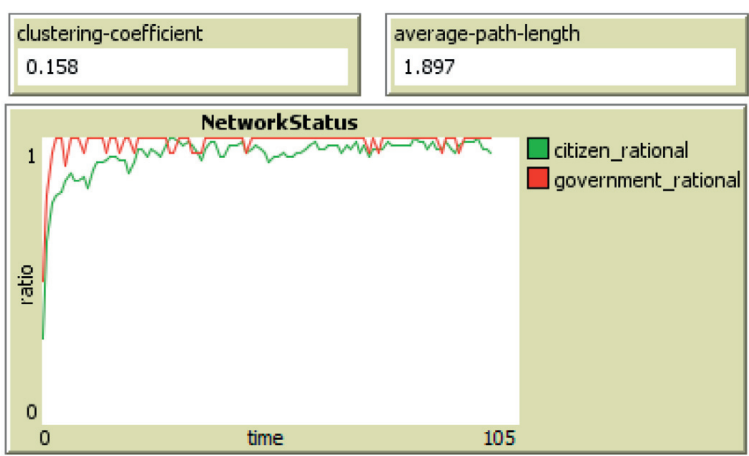

(d)

FIGURE 7: The evolutionary result when the reconnection probability $p$ takes different values in scenario three: (a) the evolutionary result when $p=0.2$; (b) the evolutionary result when $p=0.4$; (c) the evolutionary result when $p=0.6$; (d) the evolutionary result when $p=0.8$. 


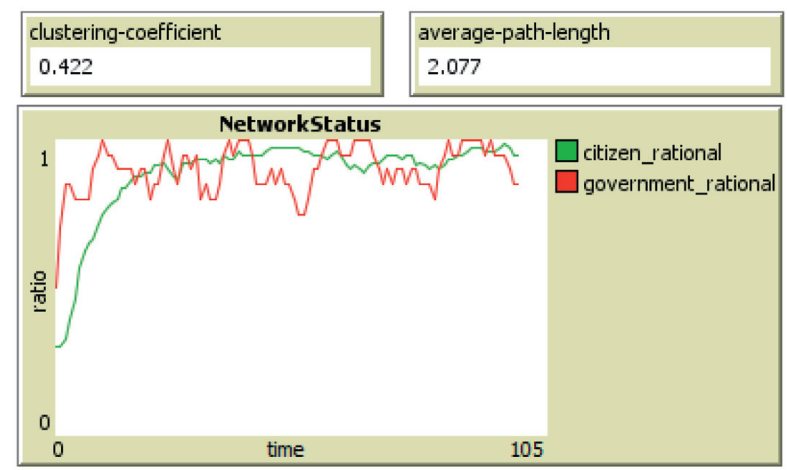

(a)

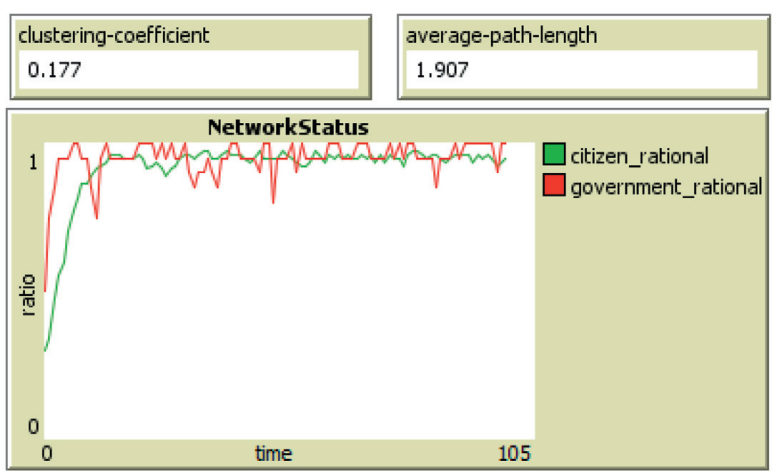

(c)

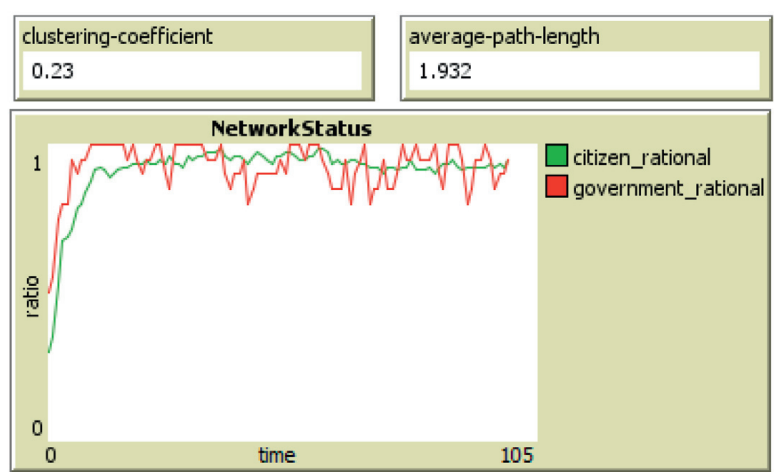

(b)

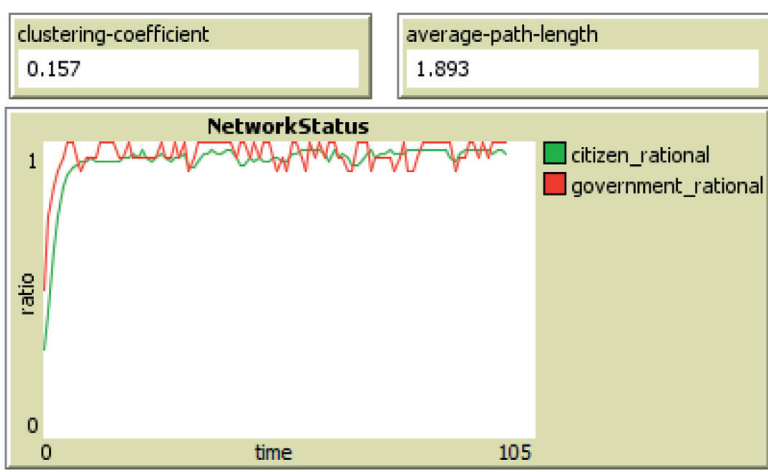

(d)

FIGURE 8: The evolutionary result when the reconnection probability $p$ takes different values in scenario four: (a) the evolutionary result when $p=0.2$; (b) the evolutionary result when $p=0.4$; (c) the evolutionary result when $p=0.6$; (d) the evolutionary result when $p=0.8$.

decrease of clustering coefficient and the average path length makes the heterogeneity among subjects more prominent. The interaction closeness among the subjects gets increased, and it is easier to achieve equilibrium state.

4.3.4. Scenario Four. The government's extra stability expenditure $\Delta S$ is small, and the resident's violent resistance cost $\Delta L$ is large.

In scenario four, the condition $(1-\alpha) R>\Delta R_{B}+(1-\beta) C>\Delta S, \quad \Delta L>\alpha R>\Delta R_{A}+\beta C \quad$ is satisfied, and the assumed parameter is set as follows: the resident's violent resistance cost $\Delta L$ is 40 and the government's extra stability expenditure $\Delta S$ of tough control is 20 . When the reconnection probability $p$ of the small-world network takes different values, the evolutionary results of the game between the resident and the government are shown in Figure 8 .

It can be seen from Figure 8 that when the reconnection probability $p$ of the small-world network takes different values, the evolutionary game trends of the resident and the government are basically the same, and the final equilibrium tends to (rational negotiation, compromised acceptance), but with the increase of reconnection probability, the time and fluctuation that they evolve to a stable state have been gradually reduced. When $p$ is 0.8 , the fluctuation of the proportion that the government chooses compromised acceptance strategy is extremely small and basically reaches a relatively stable state. When the reconnection probability $p$ is, respectively, $0.2,0.4,0.6$, and 0.8 , the network clustering coefficient is, respectively, $0.422,0.23,0.177$, and 0.157 , and the average path length is, respectively, 2.077, 1.932, 1.907, and 1.893. It also shows that with the increase of reconnection probability of the small-world network, the clustering coefficient and the average path length decrease. The decrease of clustering coefficient and the average path length makes the heterogeneity among subjects more prominent. The interaction closeness among the subjects gets increased, and it is easier to achieve equilibrium state.

\section{Conclusions}

This paper constructs an evolutionary game model between the government and the resident, which are the two key game subjects in large-scale engineering projects, and analyzes game equilibrium results and their adjustment processes of the government's extra stability expenditure and the resident's violent resistance cost in different situations. Based on the complex network formed by the interaction among the subjects, the small-world network is used as the complex network topology and the NetLogo simulation platform is used to analyze the stakeholder conflict amplification of the large-scale engineering projects on the smallworld network. The result shows as follows:

(1) In scenario one, scenario two, here it specifically refers to the initial state which is located in regions 
III and IV, scenario three, and scenario four, we find that both the final evolution results of the resident and the government are (rational negotiation, compromised acceptance). Compared with scenario two and scenario three, the resident in scenario one and scenario four has a relatively stable evolutionary state for a relatively short period of time, and the fluctuation after getting relatively stable state is also small; the possible reason is that the resident's violent resistance cost $\Delta L$ is large, and the cost that the resident chooses violent resistance strategy to express their interest appeal is too high. In most cases, they will abandon violent resistance strategy and adopt rational negotiation strategy. On the other hand, compared with scenario one and scenario three, the time that the government evolves to the equilibrium state in scenario two and scenario four is longer and fluctuates more. The possible reason for this situation is that when the government's additional stability expenditure $\Delta S$ is small, the government is prone to adopt extremely tough control strategy for its own interests to cope with the resident's interest appeal, resulting in difficulties in achieving equilibrium state or large fluctuations after getting the relatively equilibrium state. Therefore, in order to control the amplification of conflicts between the resident and the government, effective measures should be taken to increase the resident's violent resistance, that is, to increase the intensity of punishment for violent resistance. On the other hand, it should be emphasized that the government should not only consider the additional stability expenditure, but also various social impacts in many aspects when choosing tough control strategy. We cannot easily choose tough control strategy because of small stability expenditure.

(2) It can be further seen from the influence of different network characteristics on the evolution results that as the probability of network reconnection increases, the time that evolving to the relative equilibrium state decreases accordingly. This is because on the small-world network, the average path length and the clustering coefficient are correspondingly reduced due to the increase of the probability of network reconnection. On the one hand, the smaller the average path length, the smaller the scale of the conflict network between the resident and the government, the stronger the intersubjects' closeness is, and the faster the evolution process of the conflict. On the other hand, the reduction of the clustering coefficient makes the conflict network between the government and the resident presents a decentralized state, and the heterogeneity of the network is more obvious. Individuals with large nodes have greater influence, easier to influence neighboring nodes to accept their strategies and form a herd effect, so that the time that all individuals evolve to a relatively equilibrium state is reduced. On the realistic network, some individuals who are at the core status and have more social relationships have greater influence on other individuals, and the choice of their strategies will become the reference for other individuals. Therefore, for these special individuals, communication and guidance should be strengthened to minimize the choice of violent resistance strategies and to play a correct guiding role for other individuals on the network, leading other individuals to choose reasonable manners of interest appeal.

There are two limitations in this paper. Firstly, this paper combines the actual situation and literature of the construction of large-scale engineering projects in China, simplifying the multisubject conflicts into the conflict between the government and the resident, only between which the evolutionary game model is build. Secondly, in the simulation study of the large-scale engineering project conflicts on the small-world network, the hypothetical assignments of the relevant parameters such as network scale, the resident's violent resistance cost, and the government's extra stability expenditure are still not quite accurate, although they are determined on the basis of a large number of readings and interviews with relevant experts. Further research in this paper should focus on the following two aspects: firstly, further analyzing the relationships among relevant stakeholders rather than the government and the resident, considering conflicts among more stakeholders, and improving the existing evolutionary game model, and secondly, enriching the collection of relevant data and social surveys, making the selection of relevant parameters in simulation research more scientific and reasonable.

\section{Data Availability}

The data used to support the finding of this study are included within the article.

\section{Conflicts of Interest}

The authors declare no conflicts of interest.

\section{Acknowledgments}

This work was supported by the National Natural Science Foundation of China (nos. 71603070 and 71573072), the China Postdoctoral Science Foundation (no. 2019M661719), the Ministry of Education of Humanities and Social Science of China (no. 17YJC630144), and the Fundamental Research Funds for the Central Universities (no. 2019B34314).

\section{References}

[1] J. Miao, D. Huang, and Z. He, "Social risk assessment and management for major construction projects in China based on fuzzy integrated analysis," Complexity, vol. 2019, Article ID 2452895, 17 pages, 2019.

[2] B. Flyvbjerg, "What you should know about megaprojects and why: an overview," Project Management Journal, vol. 45, no. 2 , pp. 6-19, 2014. 
[3] G. Jia, F. Yang, G. Wang, B. Hong, and R. You, "A study of mega project from a perspective of social conflict theory," International Journal of Project Management, vol. 29, no. 7, pp. 817-827, 2011.

[4] E. Cuppen, M. G. C. Bosch-Rekveldt, E. Pikaar, and D. C. Mehos, "Stakeholder engagement in large-scale energy infrastructure projects: revealing perspectives using Q methodology," International Journal of Project Management, vol. 34, no. 7, pp. 1347-1359, 2016.

[5] Z.-z. Liu, Z.-w. Zhu, H.-j. Wang, and J. Huang, "Handling social risks in government-driven mega project: an empirical case study from West China," International Journal of Project Management, vol. 34, no. 2, pp. 202-218, 2016.

[6] Y. Hu, A. P. Chan, Y. Le, and R. Z. Jin, "From construction megaproject management to complex project management: bibliographic analysis," Journal of Management in Engineering, vol. 31, no. 4, Article ID 04014052, 2013.

[7] T. Yu, G. Q. Shen, Q. Shi, X. Lai, C. Z. Li, and K. Xu, "Managing social risks at the housing demolition stage of urban redevelopment projects: a stakeholder-oriented study using social network analysis," International Journal of Project Management, vol. 35, no. 6, pp. 925-941, 2017.

[8] K. Y. Mok, G. Q. Shen, R. J. Yang, and C. Z. Li, "Investigating key challenges in major public engineering projects by a network-theory based analysis of stakeholder concerns: a case study," International Journal of Project Management, vol. 35, no. 1, pp. 78-94, 2017.

[9] Z. He, D. Huang, C. Zhang, and J. Fang, “Toward a stakeholder perspective on social stability risk of large hydraulic engineering projects in China: a social network analysis," Sustainability, vol. 10, no. 4, Article ID 1223, 2018.

[10] S.-u.-R. Toor and S. O. Ogunlana, "Beyond the 'iron triangle': stakeholder perception of key performance indicators (KPIs) for large-scale public sector development projects," International Journal of Project Management, vol. 28, no. 3, pp. 228-236, 2010.

[11] R. Takim, “The management of stakeholders' needs and expectations in the development of construction project in Malaysia," Modern Applied Science, vol. 3, no. 5, pp. 167-175, 2009.

[12] K. Callan, C. Sieimieniuch, and M. Sinclair, "A case study example of the role matrix technique," International Journal of Project Management, vol. 24, no. 6, pp. 506-515, 2006.

[13] X. Lin, C. M. F. Ho, and G. Q. P. Shen, "Who should take the responsibility? Stakeholders' power over social responsibility issues in construction projects," Journal of Cleaner Production, vol. 154, pp. 318-329, 2017.

[14] J. K. Pinto and P. W. Morris, The Wiley Guide to Managing Projects, Wiley, Hoboken, NJ, USA, 2004.

[15] M. Leung, J. Yu, and Q. Liang, "Analysis of the relationships between value management techniques, conflict management, and workshop satisfaction of construction participants," Journal of Management in Engineering, vol. 30, no. 3, Article ID 04014004, 2014.

[16] J. L. Brockman, "Interpersonal conflict in construction: cost, cause, and consequence," Journal of Construction Engineering and Management, vol. 140, no. 2, Article ID 04013050, 2014.

[17] R. Awwad, B. Barakat, and C. Menassa, "Understanding dispute resolution in the Middle East region from perspectives of different stakeholders," Journal of Management in Engineering, vol. 32, no. 6, Article ID 05016019, 2016.

[18] C. Lee, J. W. Won, W. Jang, W. Jung, S. H. Han, and Y. H. Kwak, "Social conflict management framework for project viability: case studies from Korean megaprojects,"
International Journal of Project Management, vol. 35, no. 8, pp. 1683-1696, 2017.

[19] Y.Sun, "Analysis on major social problems in the three gorges reservoir area in post-migration period: their causes and the suggestions for their solution," China Soft Science Magazine, vol. 2011, no. 6, pp. 24-33, 2011, in Chinese.

[20] S. C. Wright, D. M. Taylor, and F. M. Moghaddam, "Responding to membership in a disadvantaged group: from acceptance to collective protest," Journal of Personality and Social Psychology, vol. 58, no. 6, pp. 994-1003, 1990.

[21] M. Van Zomeren, T. Postmes, and R. Spears, "Toward an integrative social identity model of collective action: a quantitative research synthesis of three socio-psychological perspectives," Psychological Bulletin, vol. 134, no. 4, pp. 504-535, 2008.

[22] M. M. M. Teo and M. Loosemore, "The role of core protest group members in sustaining protest against controversial construction and engineering projects," Habitat International, vol. 44, pp. 41-49, 2014.

[23] Z. Liu, L. Liao, and C. Mei, "Not-in-my-backyard but let's talk: explaining public opposition to facility siting in urban China," Land Use Policy, vol. 77, pp. 471-478, 2018.

[24] P. Enevoldsen and B. K. Sovacool, "Examining the social acceptance of wind energy: practical guidelines for onshore wind project development in France," Renewable and Sustainable Energy Reviews, vol. 53, pp. 178-184, 2016.

[25] M. Wang and H. Gong, "Not-in-My-Backyard: legislation requirements and economic analysis for developing underground wastewater treatment plant in China," International Journal of Environmental Research and Public Health, vol. 15, no. 11, Article ID 2339, 2018.

[26] K. Burningham, J. Barnett, and G. Walker, "An array of deficits: unpacking NIMBY discourses in wind energy developers' conceptualizations of their local opponents," Society \& Natural Resources, vol. 28, no. 3, pp. 246-260, 2014.

[27] B. Liu, Y. Li, B. Xue, Q. Li, P. X. W. Zou, and L. Li, "Why do individuals engage in collective actions against major construction projects? -An empirical analysis based on Chinese data," International Journal of Project Management, vol. 36, no. 4, pp. 612-626, 2018.

[28] W. Wang, "Risk amplification, collective action and policy game: a descriptive analysis about environmental groups struggle violence," Journal of Public Management, vol. 12, no. 1, pp. 127-136, 2015, in Chinese.

[29] D. Liu, C. Han, and L. Yin, "Multi-scenario evolutionary game analysis of evolutionary mechanism in urban demolition mass incident," Operations Research and Management Science, vol. 25, no. 1, pp. 76-84, 2016, in Chinese.

[30] S. Zhao, Y. Zhou, and Y. Cai, "Investigation on process and solution of environmental group events from NIMBY conflict perspective," China Population, Resources and Environment, vol. 27, no. 6, pp. 171-176, 2017, in Chinese.

[31] O. Kapliński and J. Tamošaitiene, "Game theory applications in construction engineering and management," Technological and Economic Development of Economy, vol. 16, no. 2, pp. 348-363, 2010.

[32] C. Li, X. Li, and Y. Wang, "Evolutionary game analysis of the supervision behavior for public-private partnership projects with public participation," Mathematical Problems in Engineering, vol. 2016, Article ID 1760837, 8 pages, 2016.

[33] C. Cohen, D. Pearlmutter, and M. Schwartz, "A game theory-based assessment of the implementation of green building in Israel," Building and Environment, vol. 125, pp. 122-128, 2017. 
[34] A. S. Barough, M. V. Shoubi, and M. J. E. Skardi, "Application of game theory approach in solving the construction project conflicts," Procedia-Social and Behavioral Sciences, vol. 58, pp. 1586-1593, 2012.

[35] C.-C. Kang, T.-S. Lee, and S.-C. Huang, "Royalty bargaining in Public-Private Partnership projects: insights from a theoretic three-stage game auction model," Transportation Research Part E: Logistics and Transportation Review, vol. 59, pp. 1-14, 2013.

[36] G. Wu, H. Wang, and R. Chang, “A decision model assessing the owner and contractor's conflict behaviors in construction projects," Advances in Civil Engineering, vol. 2018, Article ID 1347914, 11 pages, 2018.

[37] C. He, G. Jia, and J. Sun, "Governance strategy analysis of project safety behavior from the perspective of three-party game theory," Soft Science, vol. 33, no. 1, pp. 87-90, 2019, in Chinese.

[38] M. Cheng, Y. Liu, and H. Wang, "An evolutionary game analysis on the PPP projects of NIMBY facility based on system dynamics," Operations Research and Management Science, vol. 28, no. 10, pp. 40-49, 2019, in Chinese.

[39] S. He, G. Liang, and J. Meng, "Multi-subjects benefit game and behavior evolution mechanism of major engineering based on prospect theory," Science and Technology Management Research, vol. 40, no. 5, pp. 207-214, 2020, in Chinese.

[40] D. J. Watts and S. H. Strogatz, "Collective dynamics of 'smallworld' networks," Nature, vol. 393, no. 6684, pp. 440-442, 1998.

[41] A.-L. Barabási and R. Albert, "Emergence of scaling in random networks," Science, vol. 286, no. 5439, pp. 509-512, 1999.

[42] M. A. Nowak and R. M. May, "Evolutionary games and spatial chaos," Nature, vol. 359, no. 6398, pp. 826-829, 1992.

[43] C. Hauert and M. Doebeli, "Spatial structure often inhibits the evolution of cooperation in the snowdrift game," Nature, vol. 428, no. 6983, pp. 643-646, 2004.

[44] J. Vukov, G. Szabó, and A. Szolnoki, "Evolutionary prisoner's dilemma game on Newman-Watts networks," Physical Review E, vol. 77, no. 2, Article ID 026109, 2008.

[45] G. Szabó, L. Varga, and M. Szabó, “Anisotropic invasion and its consequences in two-strategy evolutionary games on a square lattice," Physical Review E, vol. 94, no. 5, Article ID 052314, 2016.

[46] R. Fan, L. Dong, W. Yang, and J. Sun, "Study on the optimal supervision strategy of government low-carbon subsidy and the corresponding efficiency and stability in the small-world network context," Journal of Cleaner Production, vol. 168, pp. 536-550, 2017.

[47] D. Liu and W. Wang, "Co-evolutionary mechanism of social network structure and strategy in mass emergency with maintain legal rights," Chinese Journal of Management Science, vol. 20, no. 3, pp. 185-192, 2012, in Chinese.

[48] Y. Bian, J. Li, and L. Xu, "Simulation and evolution model of feeding behavior in stock market based on the strategy of coordination game in network," Chinese Journal of Management Science, vol. 25, no. 3, pp. 20-29, 2017, in Chinese.

[49] Y. Fang, W. Wei, S. Mei, L. Chen, X. Zhang, and S. Huang, "Promoting electric vehicle charging infrastructure considering policy incentives and user preferences: an evolutionary game model in a small-world network," Journal of Cleaner Production, vol. 258, 2020.

[50] X. Luo, L. Hu, and D. Liu, "Social stability risk assessment of major engineering project under conditions of black-box operation and information disclosure: dynamic game analysis based on hierarchical bayesian network," Technology Economics, vol. 37, no. 10, pp. 117-130, 2018, in Chinese.

[51] M. Song and D. Liu, "Stochastic evolutionary game model for resolution mechanism of mass events," Chinese Journal of Management Science, vol. 28, no. 4, pp. 142-152, 2020, in Chinese. 